\title{
WYKORZYSTANIE WIĄZKI LASEROWEJ DO OKREŚLENIA PARAMETRÓW SZORSTKOŚCI PODŁȮ̇A I CIEPŁA JAWNEGO
}

\begin{abstract}
Streszczenie W pracy przedstawiono procedurę wyznaczania podstawowych wielkości charakteryzujących lokalne warunki przepływu powietrza oraz turbulencji termicznej. Eksperyment został przeprowadzony w tunelu aerodynamicznym przy wykorzystaniu wąskiej wiązki światła laserowego. Przydatność tej metody w odniesieniu do badań modelowych potwierdzono między innymi w pracy Consortini [1], gdzie wykazano dużą wrażliwość wiązki w przypadku krótkich ścieżek. Analizie poddany został teren o wymiarach rzeczywistych 100x100m, na którym zlokalizowany był obiekt o kształcie walca o średnicy $\phi=10 \mathrm{~m}$ i wysokości $\mathrm{h}=10 \mathrm{~m}$. Wiązka światła przebiegała prostopadle do osi tunelu. Pomiary prowadzono dla 11 ścieżek światła laserowego na wysokości $\mathrm{z}=0,12 \mathrm{~m}$, w odstępach $\Delta \mathrm{L}=0,07 \mathrm{~m}$, po stronie dowietrznej modelu. W wyniku przeprowadzonych pomiarów kąta wychylenia wiązki światła laserowego oraz jego fluktuacji możliwe było wyznaczenie głównych parametrów turbulencji tj. współczynnika struktury optycznej $C_{n}^{2}$ i skali wewnętrznej $1_{o}$, a w dalszej kolejności dyssypacji energii kinetycznej turbulencji $\varepsilon$ i współczynnika struktury termicznej $C_{T}^{2}$. Wprowadzając dodatkowe pomiary prędkości na wysokości z=0,12m możliwe stało się również oszacowanie szorstkości powierzchni terenu $z_{0}$. Przeprowadzone badania wykazały, że nawet w przypadku pojedynczego obiektu obserwowane są zmiany podstawowych parametrów przepływu oraz ciepła.
\end{abstract}

Słowa kluczowe: badania modelowe, mikroklimat, turbulencja termiczna

\section{Wprowadzenie}

Wśród czynników kształtujących mikroklimat obszarów zabudowanych istotną rolę odgrywa zabudowa. Obecność budynków wpływa zarówno na przepływ powietrza, jak również na warunki termiczne, w tym na tworzenie miejskiej wyspy ciepła. Zróżnicowanie warunków mikroklimatu winno być uwzględnione w planowaniu przestrzennym miast. Aby możliwa była ocena

${ }^{1}$ Katarzyna Klemm, Politechnika Łódzka, Instytut Inżynierii Środowiska i Instalacji Budowlanych, Zakład Gospodarki Przestrzennej i Geomatyki, Al. Politechniki 6, 90-924 Łódź; tel. 426313512; katarzyna.klemm@p.lodz.pl 
zmiennych warunków termicznych i wiatrowych potrzebne są szczegółowe dane. W praktyce pomiary podstawowych parametrów klimatycznych wykonywane są w kilku stacjach w obrębie miasta lub za pomocą badań pilotażowych. Nie odzwierciedlają zatem w pełni rzeczywistego zróżnicowania warunków mikroklimatu. W ostatnich latach podejmowane są próby wprowadzenia pewnych empirycznych klasyfikacji zabudowy określających podstawowe parametry wpływające na przepływ powietrza czy termikę, takich jak współczynnik widoczności nieba, współczynnik kanionu, współczynnik szorstkości podłoża. [2] W przypadku analiz dotyczących warunków termicznych miasta sytuacja staje się jeszcze bardziej skomplikowana. Pewnym rozwiązaniem mogą być metody scyntylacyjne, w których za pomocą wiązki światła laserowego określa się parametry turbulencji termicznej oraz wielkość ciepła jawnego emitowanego przez budynki. Jednak pomiary w skali rzeczywistej są kosztowne i czasochłonne. $\mathrm{W}$ pracy przedstawiono propozycję wykorzystania badań modelowych do określenia parametrów szorstkości podłoża, warunkujących przepływ powietrza oraz parametrów turbulencji termicznej.

\section{Teoria}

Z uwagi na zastosowanie wiązki światła laserowego do analizy przepływów turbulentnych, obserwowanych w obszarach zabudowanych (wywołanych zarówno czynnikami mechanicznymi jak i termicznymi), oparto się na teorii umożliwiającej oszacowanie strumienia pędu i $\mathrm{Q}_{\mathrm{H}}$. Odnosząc się do suchych warunków, mających miejsce w przypadku obszarów miejskich w niewielkim stopniu pokrytych roślinnością, bezwymiarowe zależności określające wielkość dyssypacji $\varepsilon$ i parametr struktury temperatury $\mathrm{C}_{\mathrm{T}}$ można zapisać

$$
\begin{aligned}
& \varepsilon=\frac{u_{x}^{3}}{\kappa\left(z-z_{d}\right)} \cdot \Phi_{\varepsilon}(\varsigma) \\
& C_{T}^{2}=\frac{T_{x}^{2}}{\left[\kappa\left(z-z_{d}\right)\right]^{2 / 3}} \cdot \Phi_{T}(\varsigma)
\end{aligned}
$$

Powyższe równania wynikają z podobieństwa Monina - Obukhova i bezwymiarowych funkcji $\Phi_{\varepsilon}(\varsigma)$ i $\Phi_{T}(\varsigma)$, zależnych od $\varsigma=\left(z-z_{d}\right) / z_{L}$

Długość Monina Obukhova $\mathrm{z}_{\mathrm{L}}$ ma postać

$$
z_{L}=\frac{u_{x}^{2}}{\kappa g} \cdot \frac{T}{T_{x}}
$$

gdzie: $T_{x}$ - skala temperatury [K],

$\kappa$ - stała Kármána 0,4,

$\mathrm{g}$ - przyspieszenie ziemskie $\left[\mathrm{m} / \mathrm{s}^{2}\right]$,

$\mathrm{u}_{\mathrm{x}}-$ prędkość tarciowa $[\mathrm{m} / \mathrm{s}]$. 


$$
T_{x}=-\frac{Q_{H}}{\rho c_{p} u_{x}}
$$

gdzie: $\mathrm{Q}_{\mathrm{H}}$ - ciepło jawne $\left[\mathrm{W} / \mathrm{m}^{2}\right]$,

$\rho$ - gęstość powietrza $\left[\mathrm{kg} / \mathrm{m}^{3}\right]$,

$\mathrm{c}_{\mathrm{p}}-$ ciepło właściwe $[\mathrm{J} /(\mathrm{K} \cdot \mathrm{kg})]$.

Wykorzystując zależność między wielkością dyssypacji $\varepsilon$ a skalą wewnętrzną turbulencji $1_{\mathrm{o}}$

$$
\varepsilon^{2 / 3}=v_{t}^{2}\left(\frac{7,4}{l_{o}}\right)^{8 / 3}
$$

gdzie: $\varepsilon$ - szybkość dyssypacji energii kinetycznej turbulencji $\left[\mathrm{m}^{2} / \mathrm{s}^{3}\right]$,

$v_{\mathrm{t}}$ - turbulentna lepkość kinematyczna [ $\left.\mathrm{m}^{2} / \mathrm{s}\right]$,

$1_{\mathrm{o}}$ - skala wewnętrzna turbulencji $[\mathrm{m}]$.

Równania (1) i (2) możemy zapisać w postaci

$$
\begin{aligned}
& u_{x}^{2}=v^{2}\left(\frac{7,4}{l_{o}}\right)^{8 / 3}\left[\kappa\left(z-z_{d}\right)\right]^{2 / 3} \Phi_{\varepsilon}^{-2 / 3}(\varsigma) \\
& T_{x}^{2}=C_{T}^{2}\left[\kappa\left(z-z_{d}\right)\right]^{2 / 3} \Phi_{T}^{-1}(\varsigma)
\end{aligned}
$$

Gdzie: $\Phi_{\varepsilon}$ i $\Phi_{T}$ są znanymi funkcjami empirycznymi wynikającymi z teorii Monina Obukhova. W pracy przyjęto $\Phi_{\varepsilon}(\varsigma)$ i $\Phi_{T}(\varsigma)$ w postaci [3]

$$
\begin{aligned}
& \Phi_{\varepsilon}(\varsigma)=[1-3 \varsigma]^{-1}-\varsigma \\
& \Phi_{T}(\varsigma)=6,3\left[1-7 \varsigma+74 \varsigma^{2}\right]^{-1 / 3} \\
& \zeta=\frac{z_{e f}}{z_{L}}<0
\end{aligned}
$$

Wykorzystując pomiary optyczne, z których uzyskujemy wielkość $C_{T}^{2}$ i $l_{o}$ dla określonych wysokości z (położenie wiązki laserowej nad powierzchnią terenu) możemy wyznaczyć wielkość $\mathrm{u}_{\mathrm{x}} \mathrm{i} \mathrm{T}_{\mathrm{x}}$ oraz $\mathrm{z}_{\mathrm{ef}}=\mathrm{z}-\mathrm{z}_{\mathrm{d}}$. Układ równań (6), (7) i (3) stanowi podstawę przy wyznaczeniu tych wielkości. Wprowadzając dodatkowe pomiary prędkości na wysokości $\mathrm{z}=0,12 \mathrm{~m}$ możliwe staje się również oszacowanie szorstkości powierzchni terenu $\mathrm{z}_{\mathrm{o}}$.

\section{Procedura wyznaczania podstawowych parametrów turbulencji}

Parametrem często stosowanym w opisie turbulencji jest parametr struktury optycznej $\mathrm{C}_{\mathrm{n}}$, który jest miarą amplitudy fluktuacji współczynnika załamania $\mathrm{n}$ i skali wewnętrznej $1_{o}$, w której energia kinetyczna turbulencji ulega dyssypacji. 
Poniżej przedstawiono propozycję wyznaczania powyższych parametrów, ograniczając rozważania do rozprzestrzeniającej się płaskiej fali spełniającej warunek

$$
l_{o}^{2} \geq \lambda L
$$

gdzie: L - długość ścieżki [m],

$\lambda$ - długość fali światła laserowego [m],

$1_{0}$ - skala wewnętrzna $[\mathrm{m}]$,

W pracy zaproponowano wprowadzenie do rozważań kąt wychylenia wiązki $\theta$. Składową poziomą i pionową $\theta_{1}$ i $\theta_{2}$ uzyskujemy, jako pochodną fazowej funkcji strukturalnej. Średnia kwadratowa kąta wychylenia jest przedstawiana, jako zależność

$$
\left\langle\theta_{1}^{2}\right\rangle^{*}=\left\langle\theta_{2}^{2}\right\rangle^{*}=3,28 \cdot 10^{3} C_{n}^{2} L\left(l_{o}\right)^{-1 / 3}
$$

gdzie: $\theta_{1}, \theta_{2}$ - składowe kąta wychylenia,

$$
C_{n}^{2} \text { - współczynnik struktury optycznej }\left[\mathrm{m}^{-2 / 3}\right] \text {. }
$$

Natomiast wyrażenie na znormalizowaną średnią kwadratową fluktuacji kąta wychylenia wiązki $\sigma_{\theta}^{2}$ zapiszemy w postaci

$$
\sigma_{\theta}^{2}=12,8 \cdot 10^{3} C_{n}^{2} L^{3}\left(l_{o}\right)^{-7 / 3}
$$

gdzie: $\sigma_{\theta}^{2}=\frac{\left\langle\theta^{2}\right\rangle-\langle\theta\rangle^{2}}{\langle\theta\rangle^{2}}$

Wykorzystując równania (12) (13) uzyskujemy wyrażenie na skalę wewnętrzną turbulencji $l_{\mathrm{o}} \mathrm{w}$ postaci

$$
l_{o}=1,97 L \sqrt{\frac{\left\langle\theta^{2}\right\rangle}{\sigma_{\theta}^{2}}}
$$

które obowiązuje w obrębie optyki geometrycznej, tj. $l_{o}^{2} \geq \lambda L$

Z przytoczonych równań (12), (13) i (14) możliwe jest wyznaczenie głównych parametrów $C_{n}^{2}$ i 1 o, opisujących przepływ turbulentny.

\section{Badania modelowe}

Korzystając z teorii podobieństwa przepływów dokonano wyboru kryteriów podobieństwa. Zapewnienie całkowitego podobieństwa w przepływach o nieustalonym charakterze jest niemożliwe do spełnienia. W tej sytuacji zdecydowano się na podobieństwo częściowe, przyjmując w pierwszej kolejności kryterium podobieństwa zjawisk okresowych. Warunek konieczny takiego przepływu wynika z równania Naviera - Stokesa i ma postać 


$$
\frac{K_{l}}{K_{t} K_{U}}=1
$$

gdzie: $\mathrm{K}_{1}$ - skala geometryczna,

$\mathrm{K}_{\mathrm{t}}$ - skala czasu,

$\mathrm{K}_{\mathrm{U}}$ - skala prędkości.

Istotnym elementem przy projektowaniu obszarów zabudowanych jest wpływ nawierzchni terenu na turbulencję termiczną. Uwzględnienie rodzaju nawierzchni w badaniach modelowych wymaga spełnienia warunku podobieństwa wynikającego $\mathrm{z}$ równania na energię kinetyczną turbulencji. Istotny staje się człon związany z produkcją energii kinetycznej turbulencji. Powyższy warunek podobieństwa ma postać

$$
\frac{K_{G b}}{K_{\rho}} \cdot \frac{K_{t}}{K_{U}^{2}}=1
$$

gdzie: $\mathrm{K}_{\mathrm{Gb}}$ - skala produkcji energii kinetycznej turbulencji

Dążąc do jednoczesnego spełnienia dwóch warunków podobieństwa należało spełnić warunek podobieństwa w postaci dwóch liczb kryterialnych.

$$
H_{o}=\frac{l}{U t} \text { oraz } G_{k l}=\frac{g \beta v T_{x} t}{U^{2} l}
$$

Badania modelowe przeprowadzone zostały przy temperaturze $\mathrm{T}=292 \mathrm{~K}$ i ciśnieniu powietrza $\mathrm{P}=1000 \mathrm{hPa}$. Obserwacje przepływu turbulentnego prowadzono spełniając warunki podobieństwa częściowego. Dla spełnienia powyższych warunków przyjęto skalę geometryczną $\mathrm{K}_{\mathrm{L}}=100$, skalę prędkości $\mathrm{K}_{\mathrm{U}}=2$, skalę czasu $\mathrm{K}_{\mathrm{t}}=50 \mathrm{i}$ skalę temperatury $\mathrm{K}_{\mathrm{Tx}}=8$. Równocześnie założono, że przyspieszenie ziemskie g, współczynnik lepkości kinetycznej $v_{t}$ oraz współczynnik rozszerzalności $\beta$ w badaniu modelowym, jak i w skali rzeczywistej są równe. Prędkość napływu powietrza w tunelu ustalono na poziomie $\mathrm{U}=1,60 \mathrm{~m} / \mathrm{s}$ dla $\mathrm{z}=0,12 \mathrm{~m}$. Jako źródło światła użyto laser półprzewodnikowy o mocy $14 \mathrm{~mW}$ emitujący falę świetlną o długości $\lambda=640 \mathrm{~nm}$ ze specjalnym układem optycznym dającym quasi równoległą wiązkę światła o gaussowskim rozkładzie natężenia światła w przekroju poprzecznym. Do detekcji natężenia światła zastosowano fotodiodę. Wiązka światła przebiegała prostopadle do osi tunelu. Pomiary prowadzono dla 11 ścieżek światła laserowego na wysokości z=0,12m, w odstępach $\Delta \mathrm{L}=0,07 \mathrm{~m}$, po stronie dowietrznej modelu.

Dysponując wspomnianym powyżej układem pomiarowym wyznaczono średni kąt wychylenia wiązki $\langle\theta\rangle$ oraz średnie standardowe odchylenie fluktuacji kąta wychylenia wiązki laserowej $\sigma_{\theta}$ dla 11 ścieżek. Korzystając ze wzorów (12), (13) i (14) określono średnią skalę wewnętrzną $l_{o}$ i współczynnik struktury optycznej $C_{n}^{2}$. W dalszej kolejności wyznaczono współczynnik struktury termicznej $C_{T}^{2}$ oraz korzystając z zależności (1), (2) szybkość dyssypacji energii kinetycznej turbulencji $\varepsilon$. 


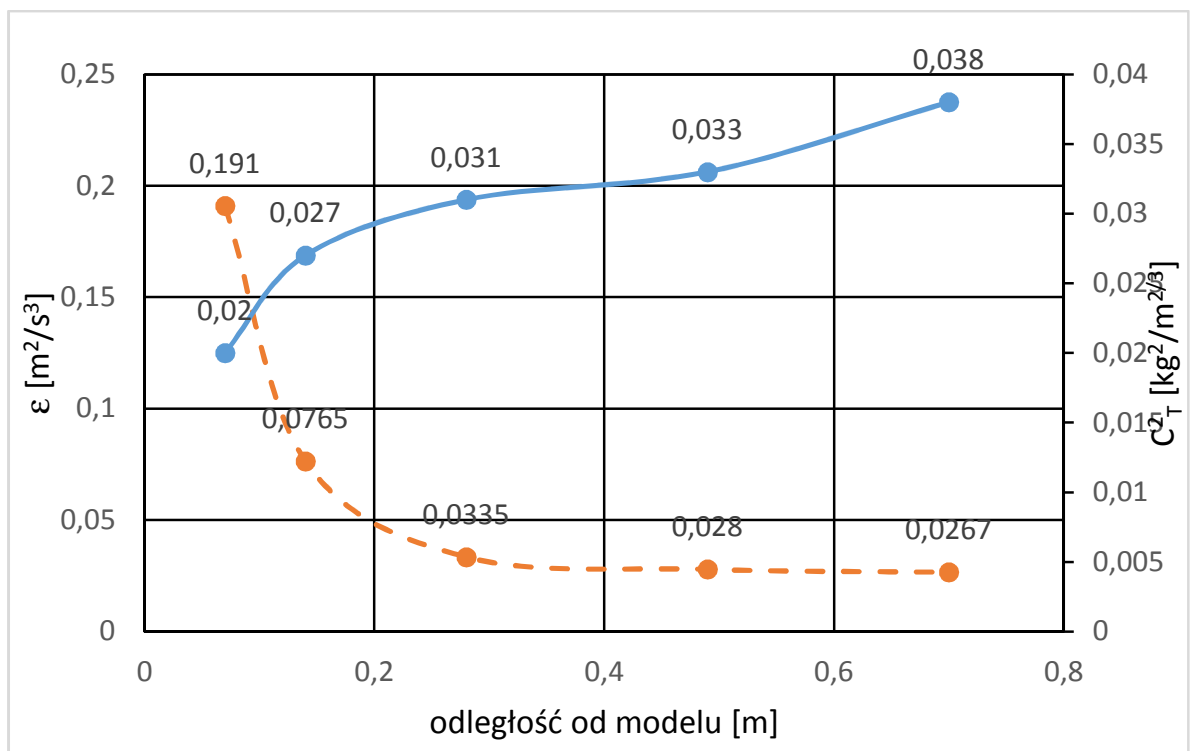

Rys. 1. Szybkość dyssypacji energii kinetycznej turbulencji oraz współczynnik struktury termicznej dla pięciu charakterystycznych ścieżek, linia ciągła - $C_{T}^{2}$, linia przerywana - $\varepsilon$

Fig. 1. Dissipation of turbulent kinetic energy and thermal structure coefficient for five characteristic paths, solid line $-C_{T}^{2}$, dottede line - $\varepsilon$

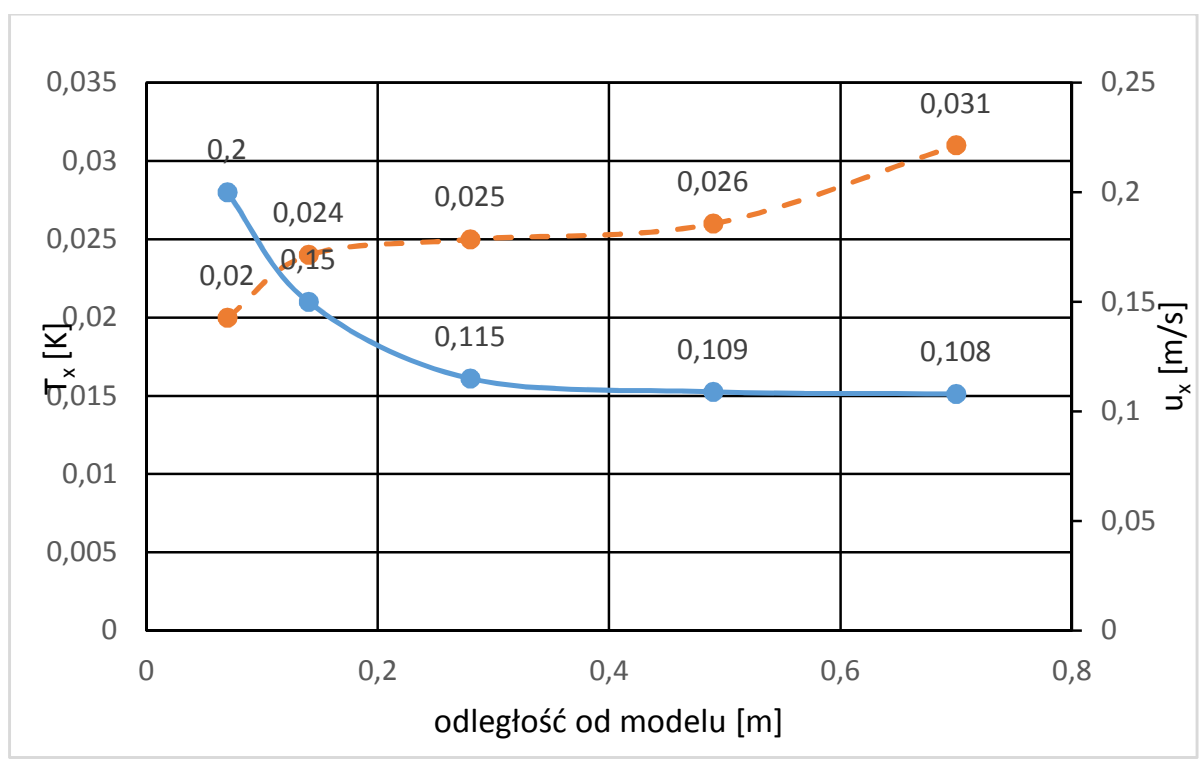

Rys. 2. Zmiany prędkości tarcia i skali temperatury $\mathrm{T}_{\mathrm{x}} \mathrm{w}$ funkcji odległości od modelu, linia ciągła $-\mathrm{u}_{\mathrm{x}}$, linia przerywana - $\mathrm{T}_{\mathrm{x}}$

Fig. 2. Changes in friction velocity and temperature scale in the function of destination from the model, solid line $-\mathrm{u}_{\mathrm{x}}$, dotted line - $\mathrm{T}_{\mathrm{x}}$ 
Na rys. 1 zamieszczono średnie wartości $\varepsilon$ i $C_{T}^{2}$ dla pięciu charakterystycznych ścieżek wiązki laserowej zlokalizowanych w odległości 0,$07 ; 0,14 ; 0,21$; 0,$49 ; 0,7 \mathrm{~m}$ od modelu.

Korzystając z układu równań (1), (2), (3) oraz przedstawionych powyżej danych i przyjętych funkcji podobieństwa $\operatorname{MOS} \Phi_{\mathrm{T}}(\zeta)$ i $\Phi_{\varepsilon}(\zeta), \zeta=\frac{z_{e f}}{z_{L}}$, możliwe stało się wyznaczenie prędkości tarcia $\mathrm{u}_{\mathrm{x}} \mathrm{i}$ temperatury $\mathrm{T}_{\mathrm{x}}$ oraz wysokości efektywnej Zef. Uzyskane wyniki przedstawione zostały na rys.2.

Uwzględniając znaną postać wzoru na gęstość ciepła jawnego oszacowano wielkość $\mathrm{Q}_{\mathrm{H}} \mathrm{W}$ warunkach prowadzonego eksperymentu. Dodatkowo określono średnią prędkość przepływu na wysokości $\mathrm{z}=0,12 \mathrm{~m}$ korzystając $\mathrm{z}$ czujników termoanemometrycznych. W oparciu o uzyskane wyniki wyznaczono współczynnik szorstkości terenu $\mathrm{z}_{\mathrm{o}}$ por. rys.3.

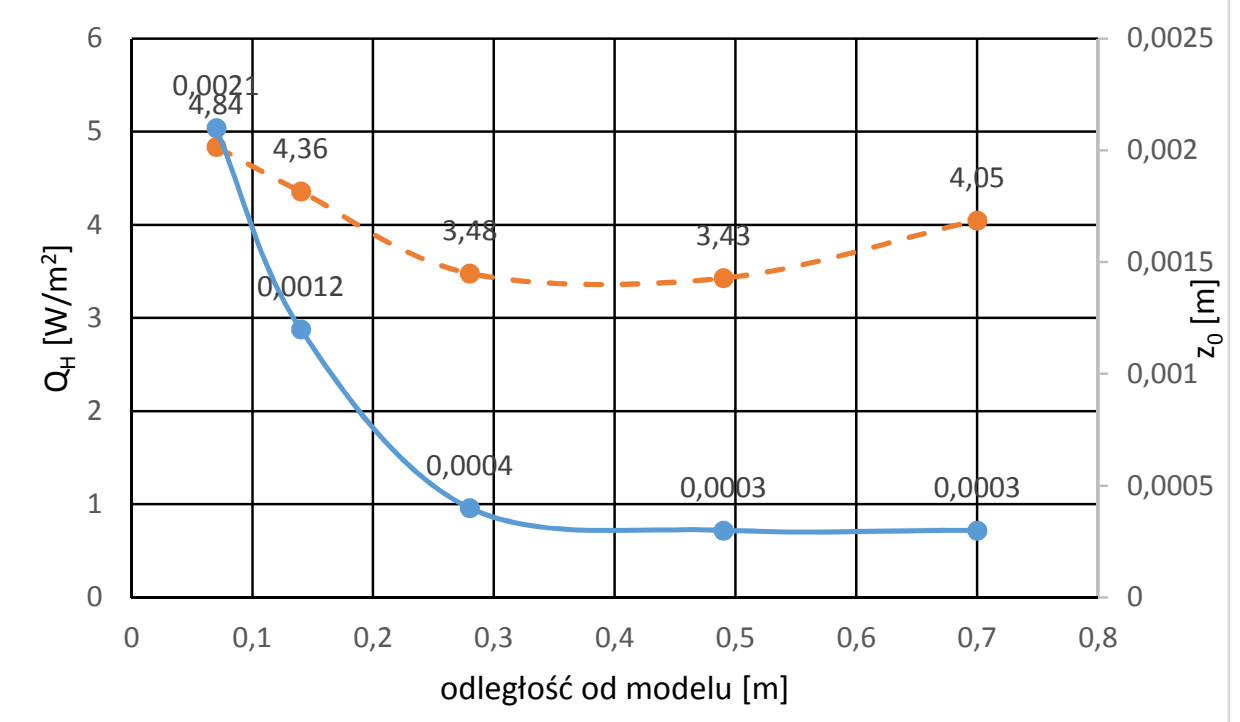

Rys. 3. Oszacowane wielkości ciepła jawnego $\mathrm{Q}_{\mathrm{H}}$ i współczynnika szorstkości podłoża $\mathrm{Z}_{\mathrm{o}}$, linia ciągła - $\mathrm{Q}_{\mathrm{H}}$, linia przerywana - $\mathrm{z}_{\mathrm{o}}$

Fig. 3. Estimated values of sensible heat and roughness length $\mathrm{z}_{\mathrm{o}}$, solid line $-\mathrm{Q}_{\mathrm{H}}$, dotted line $-\mathrm{z}_{\mathrm{o}}$

\section{Wnioski}

Pozyskiwanie danych dotyczących lokalnych warunków przepływu powietrza i turbulencji termicznej jest istotne ze względu na ich znaczenie w ocenie mikroklimatu stref miejskich. Zaznaczyć należy, że przy analizie przepływu uwzględniany jest jednocześnie wpływ turbulencji mechanicznej i termicznej. Pomiary w skali naturalnej dla uzyskania podobnych danych wymagają dłuższego okresu badań i są zależne od zaistniałych warunków meteorologicznych. 
W celu weryfikacji proponowanej przez Autora drogi pozyskiwania podstawowych danych charakteryzujących przepływy w układach zabudowy miejskiej, wskazane byłyby badania w skali naturalnej. Równie interesujące byłoby porównanie z wynikami uzyskanymi z symulacji numerycznych.

Propozycja wykorzystania badań modelowych do analizy przepływów turbulentnych w zwartych strukturach zabudowy miejskiej może stać się pomocą przy opracowywaniu map mikroklimatu miasta i stanowić bazę wyjściową dla projektantów, urbanistów i specjalistów z zakresu planowania przestrzennego.

\section{Literatura}

[1] Consortini A., Sun Y.Y., Li Z.P., Conforti G.: A mixed method for measuring the inner scale of atmospheric turbulence, Journal of Modern Optics, vol.37, No. 10, 1990, pp. 1555-1560.

[2] Stewart I. D., Oke T. R.: Local climate zones for urban temperature studies, http://journals.ametsofo c.org/doi/pdf/10.1175/BAMS-D-11-00019.1 \{dostęp 23.05. 2016 r..

[3] Thiermann V., Grassl H.: The measurement of turbulrnt surface-layer fluxes by use of bichromatic scitillation, Boundary - Layer Meteorology, 58, 1992, pp. 367-389.

\section{APPLICATION OF LASER BEAM IN DETERMINATION OF ROUGHNESS PARAMETERS AND SENSIBLE HEAT}

\section{S u m m a r y}

The paper presents a procedure for determination of the basic quantities of local wind flow and thermal turbulence. The experiment was conducted in wind tunnel with the use of the narrow laser beam. The suitability of this method in relation to the model tests were confirmed among others in work of Consortini [1], where high sensitivity of the beam for short paths has been displayed. The analysis have been subjected to an area with real dimensions of $100 \times 100 \mathrm{~m}$, where the simple object was located in the shape of a cylinder with a diameter $\phi=10 \mathrm{~m}$ and a height $\mathrm{h}=10 \mathrm{~m}$. The roughness of the surface was assumed to be equal to $z_{0}=0.02 \mathrm{~m}$. A laser beam rans perpendicular to the axis of the tunnel. Measurements were carried out for the 11 paths of the laser beam at a height $\mathrm{z}=0.12 \mathrm{~m}$ at intervals $\Delta \mathrm{L}=0.07 \mathrm{~m}$ on the upwind side of the model. The measurements of angle of deflection and fluctuations of laser beam allowed determination of basic turbulence parameters, i.e. refractive index structure parameter and inner scale and therefore dissipation of turbulent kinetic energy and thermal structure. By introducing additional measurements of speed at the height of $\mathrm{z}=0.12 \mathrm{~m}$ it was possible to estimate the roughness length $\mathrm{z}_{\mathrm{o}}$. The study showed that even in the case of a single object change of the basic flow parameters and thermal turbulence can be observed.

Keywords: model test, microclimate, thermal turbulence

DOI:10.7862/rb.2016.271

Przestano do redakcji: $17.06 .2016 r$.

Przyjęto do druku: 20.12.2016 r. 